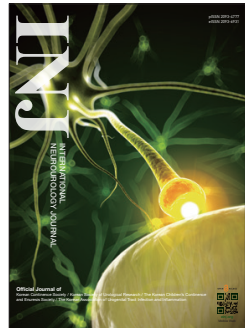

\section{Editorial}

Int Neurourol J 2020;24(4):299-300

https://doi.org/10.5213/inj.2020edi.007

pISSN 2093-4777 · eISSN 2093-6931

\title{
Memories of Using a Catheter
}

\author{
Hong Sang Moon (id https://orcid.org/0000-0003-2101-1019 \\ Department of Urology, Hanyang University College of Medicine, Seoul, Korea \\ E-mail: moonuro@hanyang.ac.kr
}

Urethral catheters are widely used by urologists for a broad range of purposes without much concern, although patients with a catheter feel very serious discomfort. The reported frequency of catheter-related bladder discomfort (CRBD) in catheterized patients is approximately $47 \%-90 \%$.

CRBD ranges from a burning sensation in the urethra to suprapubic pain and urgency, and in some cases, patients may be unable to tolerate CRBD, to the point of suffering a urethral injury while trying to remove the urethral catheter by themselves. The review article "Catheter-Related Bladder Discomfort: How Can We Manage It?" published in the December issue of International Neurourology Journal (INJ), describes the causes of CRBD associated with urethral catheters and efforts made to overcome this issue [1].

To begin with, I think that urologists' efforts to reduce CRBD have been very inadequate. Few studies have been conducted with the goal of reducing CRBD, and most such studies tried to reduce CRBD by using oral drugs [2-5]. There is a significant body of research results reported by anesthesiologists on the use of drugs that can reduce CRBD under anesthesia for patients who are catheterized during surgery. However, the drugs used by anesthesiologists are not suitable for urologists to prescribe. There are limited published research results aimed at reducing CRBD by improving the urethral catheter itself, and none of the commercially available catheters have been recognized as being able to effectively reduce CRBD.

My personal experience with a urethral catheter served as an opportunity to embark upon research on CRBD. I underwent a robot-assisted radical prostatectomy for prostatic adenocarcinoma (Gleason score 7; 3+4) 4 years ago, and at that time I had a urethral catheter inserted for several days. The pain caused by the urethral catheter was more difficult to bear than the pain at the surgical site. This prompted to me to reflect on how I was using such an inconvenient and uncomfortable device on patients without much thought, and I started to think about whether there could be a more convenient catheter and whether it would be possible to develop a way to reduce CRBD with urethral catheters. Since then, I have been conducting research on this topic in collaboration with professors of the Department of Biomedical Engineering, but the development of a new device has been challenging.

I would like to share the news about INJ. INJ signed an MOU with International Society for the Study of Bladder Pain Syndrome (ESSIC) in December 2020, and INJ have become the official journal of ESSIC. ESSIC is an academic society founded in 2004, and it publishes many excellent studies on bladder pain syndrome.

I believe that the cooperation between the two organizations will make progress for both INJ and ESSIC, and I am grateful to President Wyndaele, Vice President Cervigni and Prof. Birder for helping the two organizations form an MOU.

Also, I would like to express my sincere gratitude to the many people who have generously helped INJ over the past year, especially INJ's associate editors (Prof. Khae Hawn Kim, Prof. Young Sam Cho, and Prof. Su Jin Kim), Deputy Editors-inChief (Prof. Karl-Erik Andersson and Prof. Lori Birder), and manuscript editor (Hwan Tae Ahn).

Happy new year!

- Conflict of Interest: No potential conflict of interest relevant to this article was reported. 


\section{REFERENCES}

1. Jang EB, Hong SH, Kim KS, Park SY, Kim YT, Yoon YE, et al. Catheter-related bladder discomfort: how can we manage it? Int Neurourol J 2020;24:324-31.

2. Bala I, Bharti N, Chaubey VK, Mandal AK. Efficacy of gabapentin for prevention of postoperative catheter-related bladder discomfort in patients undergoing transurethral resection of bladder tumor. Urology 2012;79:853-7.

3. Chung JM, Ha HK, Kim DH, Joo J, Kim S, Sohn DW, et al. Evaluation of the efficacy of solifenacin for preventing catheter-related bladder discomfort after transurethral resection of bladder tumors in patients with non-muscle invasive bladder cancer: a prospective, randomized, multicenter study. Clin Genitourin Cancer 2017;15: $157-62$.

4. Maghsoudi R, Farhadi-Niaki S, Etemadian M, Kashi AH, Shadpour P, Shirani A, et al. Comparing the efficacy of tolterodine and gabapentin versus placebo in catheter related bladder discomfort after percutaneous nephrolithotomy: a randomized clinical trial. J Endourol 2018;32:168-74.

5. Clarke H, Bonin RP, Orser BA, Englesakis M, Wijeysundera DN, Katz J. The prevention of chronic postsurgical pain using gabapentin and pregabalin: a combined systematic review and meta-analysis. Anesth Analg 2012;115:428-42. 